electrostatic control could perhaps be obtained using localized charges.

The article by Wolkow and colleagues is one of a series of contributions $s^{1,12,13,16,17}$ that underline the potential of molecular transport junctions using silicon electrodes, and explore the different control mechanisms and mechanistic transport behaviours that can be observed in them. Using a semiconductor electrode substantially widens the perspective on singlemolecule transport structures, the basic unit of molecular electronics.

Mark Ratner is in the Department of Chemistry, Northwestern University, 2145 Sheridan Road, Evanston, Illinois 60208-3113, USA.

e-mail: ratner@chem.northwestern.edu

1. Piva, P. G. et al. Nature $435,658-661$ (2005)

2. Bowler, D. R. J. Phys. Condens. Matter 16, R721-R754 (2004).

3. Nitzan, A. \& Ratner, M. A. Science 300, 1384-1389 (2003).

4. Reed, M. A. \& Takhee, L. (eds) Molecular Nanoelectronics
(American Scientific, Stevenson Ranch, CA, 2003).

5. Nitzan, A. Annu. Rev. Phys. Chem. 52, 681-750 (2001)

6. Datta, S. Quantum Transport: Atom to Transistor (Cambridge Univ. Press, 2005).

7. Tour, J. M. Molecular Electronics: Commercial Insights, Chemistry, Devices, Architecture and Programming (World Scientific, River Edge, NJ, 2003).

8. Xiao, X. Y., Xu, B. Q. \& Tao, N. J. Nanoletters 4, 267-271 (2004)

9. Mayor, M. \& Weber, H. B. Angew. Chem. Int. Edn Engl. 43, 2882-2884 (2004).

10. Basch, H., Cohen, R. \& Ratner, M. A. Nanoletters (in the press).

11. Lewis, P. A. et al. J. Am. Chem. Soc. 126, 12214-12215 (2004)

12. Guisinger, N. P. et al. Nanoletters 4, 55-59 (2004).

13. Tong, X., DiLabio, G. A. \& Wolkow, R. A. Nanoletters 4, 979-983 (2004).

14. Hamers, R. J. et al. Acc. Chem. Res. 33, 617-624 (2000).

15. Filler, M. A. \& Bent, S. F. Prog. Surf. Sci. 73, 1-56 (2003)

16. Hersam, M. C., Guisinger, N. P. \& Lyding, J. W. Nanotechnology 11, 70-76 (2000).

17. Rakshit, T. et al. Nanoletters 4, 1803-1807 (2004).

18. Xue, Y. Q. \& Ratner, M. A. Int. J. Quant. Chem. 102, 911-924 (2005).

19. Liang, W. J. et al. Nature $417,725-729$ (2002)

20. Park, J. et al. Nature $417,722-725$ (2002)

\title{
GENE THERAPY
}

\section{The moving finger}

Katherine A. High

\section{DNA-cleaving enzymes trigger a repair process that can now be harnessed to correct mutations in the human genome in vitro. This represents another step towards gene-correction strategies for treating human disease.}

Genetic engineering and gene-transfer technologies have produced a wealth of new ideas about how to treat genetic diseases. Many of these have been applied quite successfully in cultured cells and even in mouse models of human disease, but have proven remarkably difficult to translate into clinical practice. On page 646 of this issue, however, Urnov and colleagues ${ }^{1}$ report a new strategy that combines two biological processes that are highly evolutionarily conserved to correct a genetic mutation in human cells. Their success rate is theoretically high enough to result in clinical benefit. Their findings, building on and extending previous studies of this strategy $y^{2,3}$, are a considerable step towards a successful genetic-engineering approach to treating human disease.

Most gene-transfer strategies are in essence gene-addition therapies: a normal copy of a gene is transferred into the cell type of interest, where it coexists with the mutant copy of the same gene. But the ultimate aim is to correct the mutation, and thus enable the production of a normal protein under the control of the cell's intrinsic regulatory signals. So far this goal has remained out of reach for human therapeutics because it is difficult to correct genes at a high enough frequency to be of clinical benefit.

Site-specific correction of a mutation can be divided into three distinct problems. First, the site to be corrected must be detected among the three billion base pairs of the genome. Second, the specific base change must be installed. And third, the 'detecting and correcting' reagents must be efficiently delivered to the relevant cell type in the body (for example, lung cells in patients with cystic fibrosis). To solve the first problem, Urnov et al. ${ }^{1}$ have exploited zinc-finger nucleases (ZFNs). These synthetic proteins were first described by Chandrasegaran and colleagues ${ }^{4}$. Developed as reagents to cleave DNA at a specific site, they are composed of a DNA-binding domain plus a DNA-cleaving domain.

The DNA-binding domain of a ZFN comprises a string of 'zinc-finger motifs', each a stretch of around 30 amino acids, stabilized by a zinc ion, that binds to a particular threebase DNA sequence. The zinc-finger aminoacid sequence varies according to the DNA sequence to which it binds. There are 900 zincfinger-bearing proteins encoded in the human genome $^{5}$, affording an extensive working catalogue for the assembly of ZFNs that bind

\section{ANALYTICAL CHEMISTRY The Renaissance palette}

The invention of printing using movable metal type - at least in Europe - is attributed to Johann Gutenberg of Mainz, in present-day Germany. His discovery profoundly influenced Western culture by allowing, in theory, the 'mass' reproduction of religious and secular texts. In practice, however, the printed copies were distributed to workshops throughout Europe to be lavishly embellished, or 'illuminated', by hand with headlines and capital letters.

Of the estimated 180 copies of the Bible that Gutenberg produced in three years up to 1455, substantial fragments of 48 survive. Tracey D. Chaplin et al. (Anal. Chem. doi:10.1021/ac050346y) have used
Raman spectroscopy — shining laser light onto a sample and analysing the spectrum of the scattered light - to study the chemical composition of the pigments used in the illuminations of seven copies of the Bible from libraries in France, Germany and Britain. Although the style of illumination varies widely between the Bibles, the chemical composition of the pigments used is remarkably similar, pointing to a shared knowledge of dyestuffs across fifteenth-century Europe. Nine pigments are present, for example, in the King George III Bible (pictured) held in the British Library in London. The chemical composition of seven could be identified

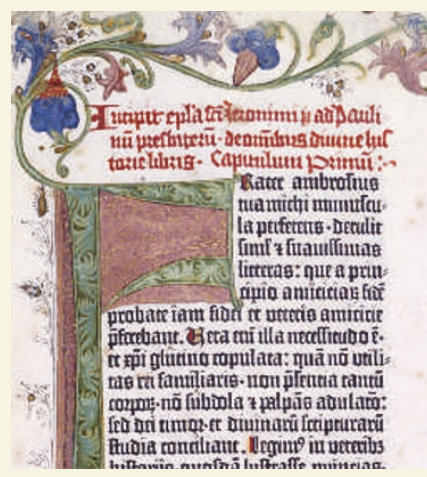

conclusively: red (cinnabar or mercury sulphide), blue (azurite, a basic copper carbonate), olive green (malachite, another basic copper carbonate), dark green (verdigris, an organo-copper compound), yellow (lead-tin oxide), black (carbon) and white (calcium carbonate). Copies of the Bible from two German libraries, printed on vellum, also contain the

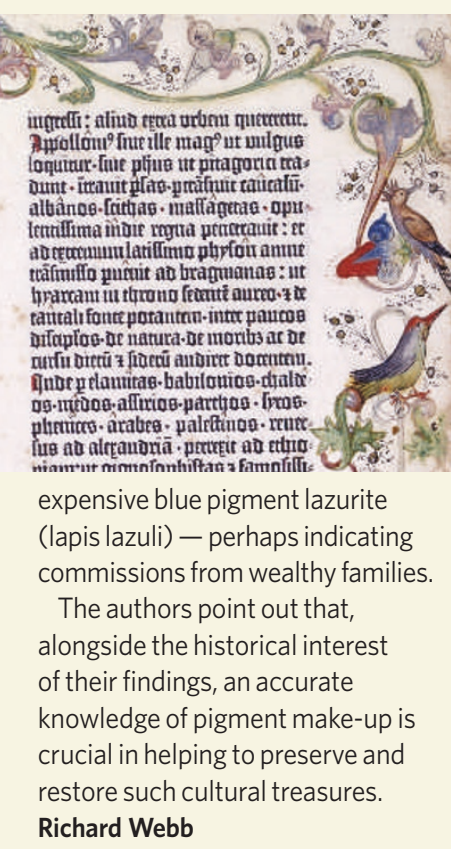

